Research Article

\title{
Influence of Full-Life Cycle Wheel Profile on the Contact Performance of Wheel and Standard Fixed Frog in Heavy Haul Railway
}

\author{
He Ma ${ }^{D}$, Jinming Zhang $\mathbb{D}^{D}$, Jun Zhang $\mathbb{D}^{D}$, Tao Tao Jin $\mathbb{D}^{D}$, and Chun Yu Song ${ }^{1}$ \\ School of Mechanical-Electronic and Automobile Engineering, Beijing University of Civil Engineering and Architecture, \\ Beijing 100044, China \\ Correspondence should be addressed to Jun Zhang; zhangjun611@bucea.edu.cn
}

Received 5 September 2020; Revised 28 October 2020; Accepted 13 November 2020; Published 26 November 2020

Academic Editor: Nicolo Zampieri

Copyright $(2020 \mathrm{He}$ Ma et al. This is an open access article distributed under the Creative Commons Attribution License, which permits unrestricted use, distribution, and reproduction in any medium, provided the original work is properly cited.

Wheel wear is unavoidable, which affects the contact performance of the wheel and rail. This article explores the effects of wheel profile wear on the static contact and dynamic interaction between wheel and standard fixed frog in heavy haul railway. The coupling dynamic models of the vehicle-fixed frog system are established to calculate the change regulation of displacement, contact force, and acceleration when a vehicle passes through the standard fixed frog at a speed of $50 \mathrm{~km} / \mathrm{h}$ in the facing move in the diverging line. Besides, the finite element models of wheel and standard fixed frog at key positions are developed to simulate the contact patch and distribution of von Mises stress in the regions of the wheel-fixed frog. Compared with the standard profile, the maximum lateral displacement of the worn profile can be reduced by up to $9 \mathrm{~mm}$. The vertical contact force can be reduced from $750 \mathrm{kN}$ to $320 \mathrm{kN}$, and the decrease is $57.3 \%$. The von Mises stress could decrease up to $34 \%$ compared with the standard. And the results show that the wheel profile wear changes the positions of the wheel-rail contact points along the longitudinal direction and affects the dynamic interaction of vehicle and standard fixed frog. For the measured worn wheel profiles in this article, profile wear relieves the dynamic responses and it is good for the nose rail.

\section{Introduction}

Turnout (switch and crossing) is a crucial part of the railway system, which enables the train to run from one track to another. Many types of turnouts are available, while the single turnout is the most common. Single turnout consists of a switch panel and crossing panel which are connected by a closure panel. The fixed and movable turnout are two kinds of turnout. The structure of the fixed turnout is simple, while the simplicity of its structure results in the inevitable "harmful space" problem. The gap between the narrowest point of the two wing rails and the tip of the nose rail is called the "harmful space," as shown in Figure 1. Although the movable turnout could avoid the "harmful space," it requires more maintenance and entails higher cost because of its complex structure [1]. Moreover, the movable turnout is not suitable for the transportation mode of heavy haul railways; those are large axle weight, high density, and large freight volume. Thus, the fixed turnout accounts for more than 90 percent of turnouts which are used in heavy haul railways [2-4].

In the crossing panel of single fixed turnout, the crossing rail is composed of fixed frog (nose rail and wing rail) and check rail. When the train passes through the crossing panel in the facing move (the wheel runs on the wing rail to the nose rail), it is possible that the wheel might go wrong and cause the train to derail. This is the purpose of setting the check rail, which is to force the direction of the wheels.

In the process of the wheel passing through the turnout in the facing move, the wheel has an impact on the nose rail. While, in the trailing move (the wheel runs on the nose rail to the wing rail), the wheel has an impact on the wing rail. Due to the inevitable "harmful space" and the inherent 


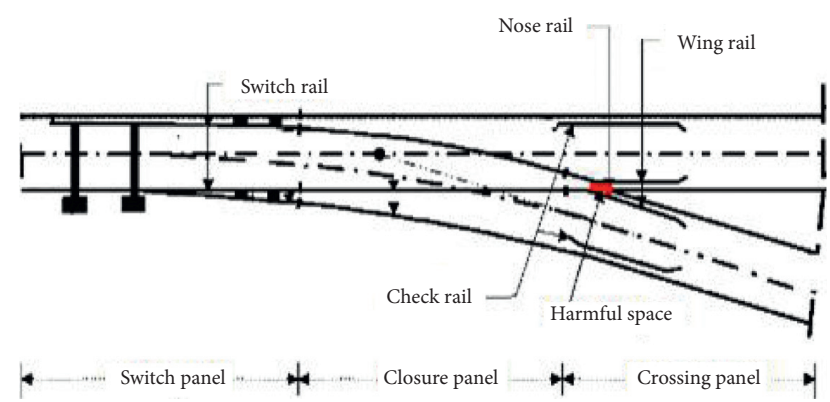

Figure 1: Single turnout.

structural irregularity of the fixed frog, severe vibration will occur, affecting the safety of train operation and the speed.

Wheel-rail contact behavior in the crossing has been studied with a number of laboratory experiments and numerical procedures. Lateral and vertical dynamic force and wheel contact angle with different speed were studied in the turnout aera $[5,6]$. The characteristics of the wheel-rail contact geometry relationship of the turnout zone are studied by Ren and Sun [7]. Then, they investigated the influence of the nose rails height on the wheel-rail contact characteristics by the high-speed vehicle/turnout dynamic model [8]. Besides, a vehicle/turnout system dynamic model was established to analyze the dynamics capability while passing through the turnout [9]. A model on the basis of the vehicletrack coupling dynamic theory was established by Zhai and Wang to study on the safety of trains when the locomotive passes through the branch line of turnout. In addition, they investigated the influence of running speed [10].

Based on No. 42 high-speed turnout, a wheel/rail contact model, with different point hiding tip structures and wheel profiles, was established to analyze the characteristics of irregularity in the crossing zone [11]. Li et al. [12] established a wheel-crossing finite element contact model to study the contact trails, characteristics, and Mises stress. Wiest et al. [13] assessed four methods based on calculating contact stress, contact patch size, and penetration depth in wheel-rail or switch contact. The four models are as follows: Hertz and non-Hertzian method implemented in the computer program CONTACT and elastic and elastic-plastic finite element contact models investigated with the commercial code ABAQUS. The findings showed that the contact pressure distributions calculated in Hertz and CONTACT are consistent with the results acquired from the finite element method, as long as there is no plastification of the material. And the literature [14] presented a dynamic finite element model for the process of a wheel passing the frog. This model accounts for the dynamic process, the elastic deformations of the wheel, and the elastic-plastic deformations of the crossing. In order to simulate the situation in which the wheel passes through the frog, the finite element models have been developed by Pletz et al. [15]. The dynamic response of the wheel passing through the frog and the variation laws of the contact stress and contact status were concluded.

The above experts ignore the influence of wheel wear on the wheel-rail relationship. The wheels wear leads to wheel profile change and, thus, strongly affects the dynamic performance of vehicles and the static contact performance. The calculation of dynamic and static contact performance makes it possible to properly design the profile of the fixed frog. Xu et al. [16] studied the contact analysis and dynamic response of worn rail in the switch rail area of high-speed train turnout. Chen et al. [17] studied the influence of wheel profile evolution on the dynamic interaction between the wheel of high-speed railway and the switch rail in the turnout. While in heavy haul railway, the fixed frog is utilized. And the dynamic response is different from the movable frog used in the high-speed railway.

In this paper, the contact between the wheel which concluded the full-life cycle profile and the standard fixed frog is studied in the simulation software Simpack and ABAQUS. The influences of wheel profile wear on the wheel/ standard fixed frog contact performance are accounted for in the simulation. Nominal and measured worn wheel profiles are used as boundary conditions of wheel-standard fixed frog contact. The effects of full-life cycle wheel profile on the wheel-rail static contact status and dynamic interaction of vehicle and standard fixed frog in heavy haul railway are researched. In practice, the frog will also be worn with the increase of service time. Therefore, future work will study the contact between wheel profile and wear frog.

\section{Wheel and Fixed Frog Profiles}

With the increase of trains, the profiles of wheel and fixed frog change with cumulative abrasion. A series of work has been conducted to track and test the evolution of wheel profiles in heavy haul railway, as is shown in Figure 2. Worn wheel profiles are measured using the instrument named CALIPRI, a wheel-rail profile measuring instrument. Use the CALIPRI to measure the worn profile of the wheelsets in the field. And, then, import the profile wireframe scanned by the infrared ray of the CALIPRI into the HYPERMESH. The profile of the wheel is discretized. The discrete point data is generated into prr files and imported into the Simpack to become a usable worn profile. Nominal profile represents the LM. Profiles I, II, III, and IV are all measured worn profiles whose vertical wear loss in the radius of the rolling circle is, respectively, $1.318 \mathrm{~mm}, 2.622 \mathrm{~mm}, 3.861 \mathrm{~mm}$, and $5.759 \mathrm{~mm}$. The figure shows that the abrasion on the tread is more severe compared with that on the flange. Moreover, with the wear of the wheel, its conicity on the tread decreases gradually. Hence, the tread flattens out. Profile I and profile II are called initial worn profiles and profile III and profile IV are called late worn profiles based on the wear loss.

The nominal geometry of the studied turnout is a standard design CN75-350-1:12 (curve radius $350 \mathrm{~m}$, turnout angle $1: 12$ ). According to the change of nose rail width and the location of frog injury researched in field, the key sections of the theoretical nose of crossing (Section A) and $10 \mathrm{~mm}$ (Section B), $20 \mathrm{~mm}$ (Section C), $30 \mathrm{~mm}$ (Section D), $40 \mathrm{~mm}$ (Section E), and $50 \mathrm{~mm}$ (Section F) $\mathrm{mm}$ width of nose rail, respectively, are analyzed. The variation of rail profiles along the turnout is accounted for by sampling the rail cross sections at several key positions, as shown in Figure 3. The spline interpolation method is used to stretch 


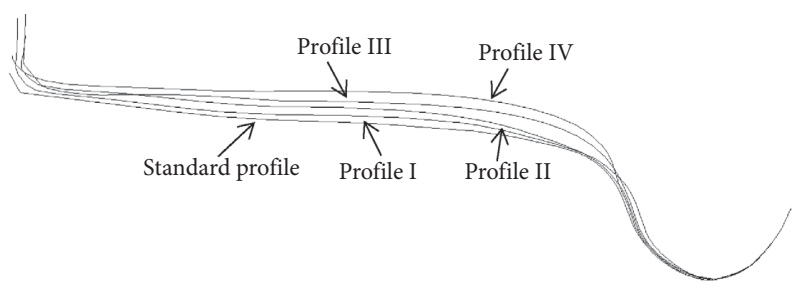

Figure 2: Wheel profiles at different abrasion stages.

the key sections to form the required frog in dynamic software SIMPACK.

\section{Calculation of Wheel-Fixed Frog Contact Geometry}

When the vehicle passes through the turnout, the wheel-rail contact positions could be predicted at the crossing panel. It may be the wheel flange or tread contacts with the nose rail or the outside of the wheel tread contacts with the wing rail.

The minimum distance method is used to determine the contact point pairs between wheels and frogs, as shown in Figure 4 . The wheel-rail contact point pairs between different wheel profiles and fixed frog at Sections D and E calculated through the principle are indicated in Figure 5. At Section E, the wheels with different worn profiles all contact with the nose rail at different lateral displacements. And at Section D, the wheel with nominal profile, profile I or profile II contacts with the nose rail. With the wear of the wheel, the wheel tread wears more seriously than the outside of the wheel tread. Therefore, the wheel with profile III or profile IV contacts with the wing rail when the wheel-rail lateral displacement ranges from -3 to $15 \mathrm{~mm}$ at Section D.

\section{Dynamic Interaction of Vehicle and Fixed Frog}

4.1. Vehicle-Turnout Dynamic Model. The vehicle-turnout dynamic model is simulated in the commercial software SIMPACK. The calculation model (see Figure 6) includes two parts: the vehicle model of the Chinese C80 wagon in Datong-Qinhuangdao heavy haul railway and the turnout railway, which are connected by a wheel-rail contact model.

The calculation model of the vehicle includes carbody, primary and secondary suspension elements, frames, and wheelsets. In the three-dimensional multibody dynamic model of the vehicle, carbody, frames, and wheelsets are implemented as rigid bodies, and the parameters of the vehicle are listed in Table 1. The rotary K6 bogies used in C80 trucks are three-piece truck bogies of cast steel. The rotary K6 bogie adopts the axle box elastic shear pad as the primary suspension and the central pillow spring suspension system with variable friction damping device as the second suspension, in which the second stage stiffness adopts the pillow spring and, equipped with JC double-acting, often contacts elastic side bearing. A lower cross support device with side frame elasticity is arranged along the horizontal plane between the two sides of the frame, which can effectively hinder the rhombic deformation between the two sides of the frame and then improve the rhombic stiffness of the bogie. This would help to improve the stability of the bogie in operation.

The track is described by the discrete track and sleeper model, and the trackpad follows the single support model. In considering the sleeper mass, the track and sleeper are considered part of the route. The spring-damping models in the lateral and vertical directions are employed to connect with the ground. The variations in rail cross section and wheel wear are considered in the calculation dynamic model. The vehicle is switching into the turnout track in facing move in the simulation.

The wheel-rail relationship is very complex in the turnout railway because of the variation of rail profiles. The wheel-rail geometry has been calculated in advance. The precalculated contact points between wheel and rail have been saved in tables and would be utilized in dynamic analysis. The contact points and contact angle determine the locations and directions of contact force, respectively. MultiHertzian contact theory is used to solve the normal contact problem and the FASTSIM algorithm is applied for calculation of the tangential contact force.

The dynamic calculation could predict the motion of all parts of the vehicle and forces between different parts. The dynamic responses, such as wheel-rail contact force and relative displacement between wheel and rail could be used as inputs in the following finite element models.

To simplify the calculation, the model will make the following assumptions. The plastic deformation of the contact zone and the elastic deformation of the rail are not considered. Although there will be wear and tear in the service of the train, the frog profile used in this paper is standard. Likewise, the ballast under the track is not considered.

4.2. Dynamic Responses. When the vehicle reverse passes through the fixed frog in the facing move, the wheel first enters the throat area $(-373.6 \mathrm{~mm} \sim-733.4 \mathrm{~mm}$ from the theoretical nose of crossing) of the frog, then passes through the theoretical nose of crossing, and finally transitions from the wing rail to the nose rail (transition zone) until it is in full contact with the nose rail.

The effects of wheel profiles wear on the dynamic interaction between vehicle and fixed frog in heavy haul railway are researched and the simulation is carried out at the speed of $50 \mathrm{~km} / \mathrm{h}$ for the vehicle. The results conclude the lateral and vertical displacement of wheelset, the vertical contact force at the side of the crossing panel, and the vertical acceleration of carbody (the mass center of carbody), shown in Figure 7 . The $x$-axis represents the positions along the longitudinal direction of the crossing panel, and number $0 \mathrm{~m}$ in the $x$-axis represents the theoretical point of the frog.

As can be seen from Figure 7(a), the lateral displacement of all profiles reaches a maximum in front of the theoretical nose of crossing and in the transition zone. The standard profile reaches the maxima before the theoretical nose; the value is $9 \mathrm{~mm}$. Profile II reaches the maxima in the transition zone, and the value is $7 \mathrm{~mm}$. Overall, the lateral displacement 


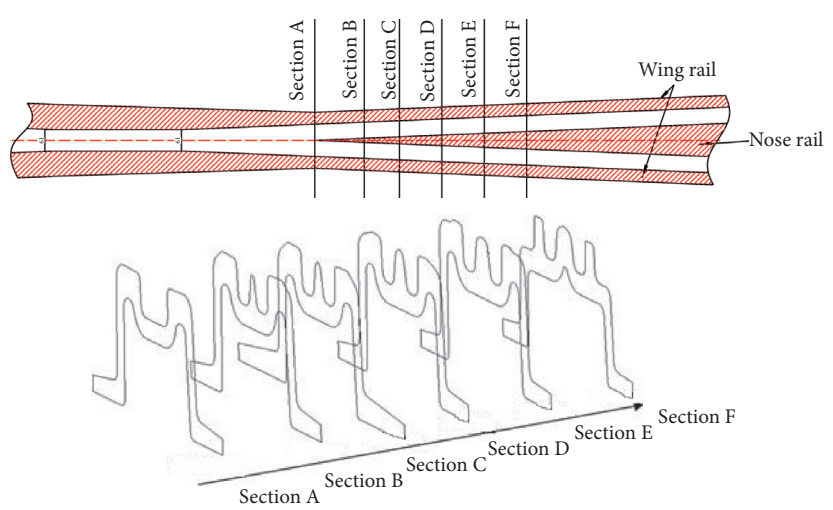

Figure 3: Cross sections of the fixed frog.

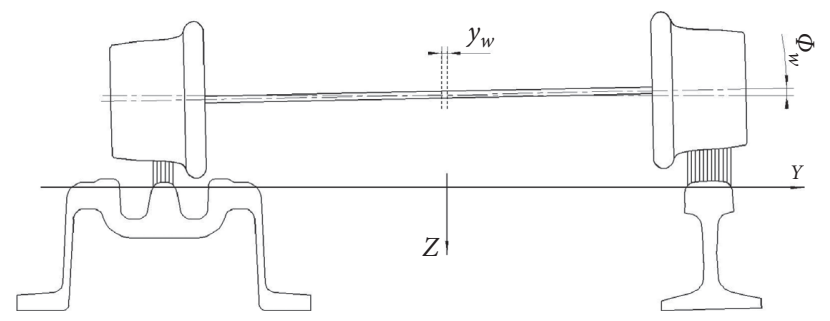

FIgURE 4: Determination of wheel-rail contact points.
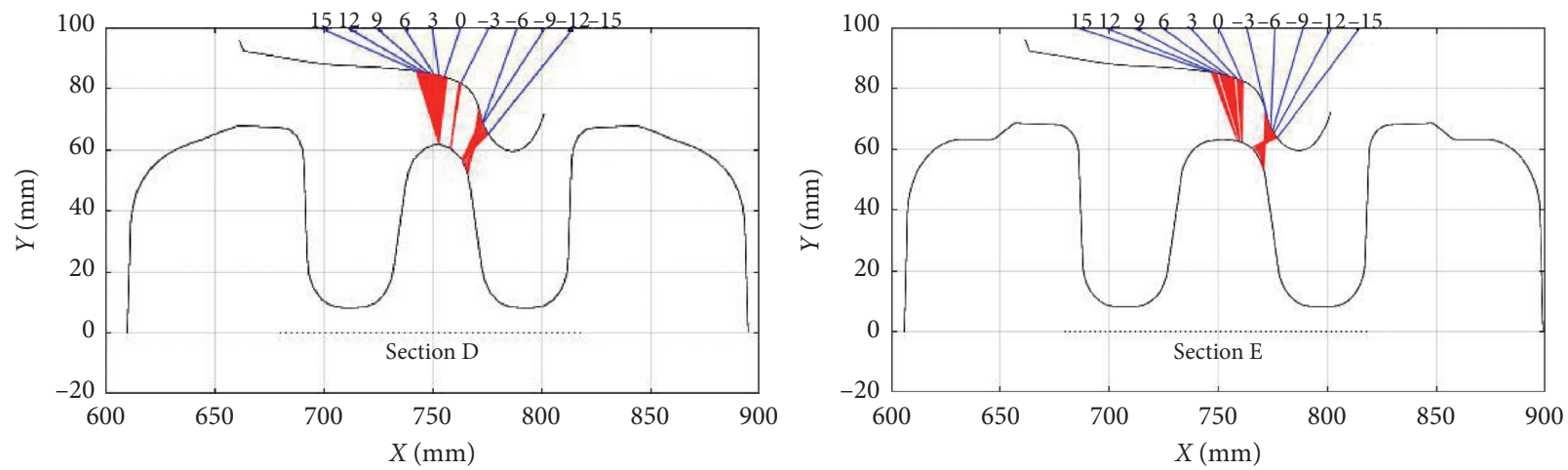

(a)
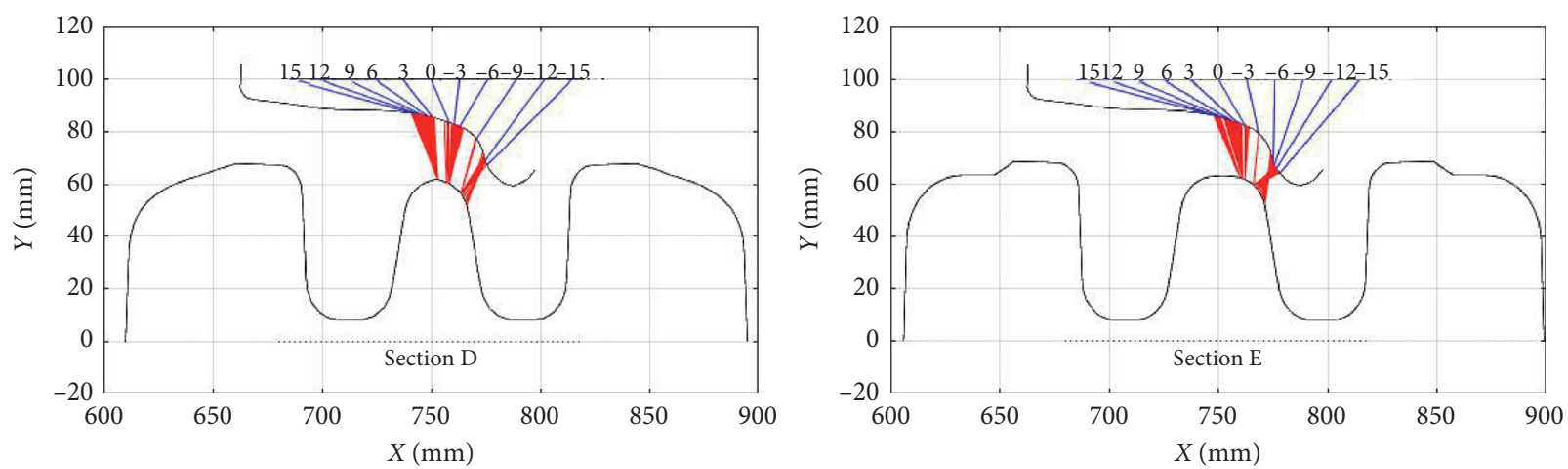

(b)

Figure 5: Continued. 

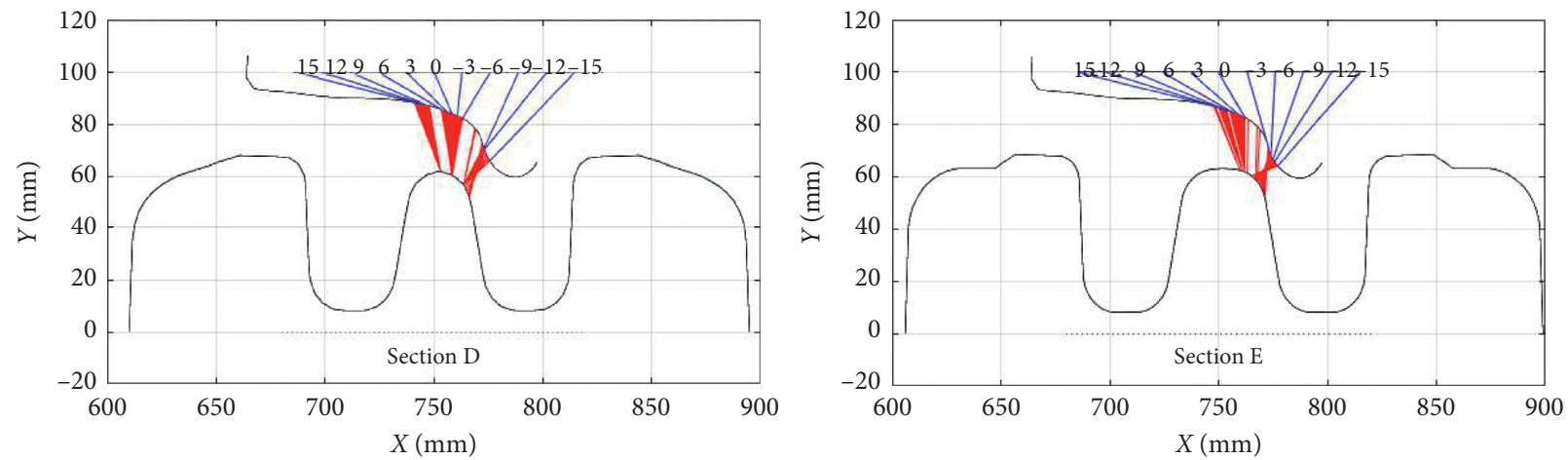

(c)
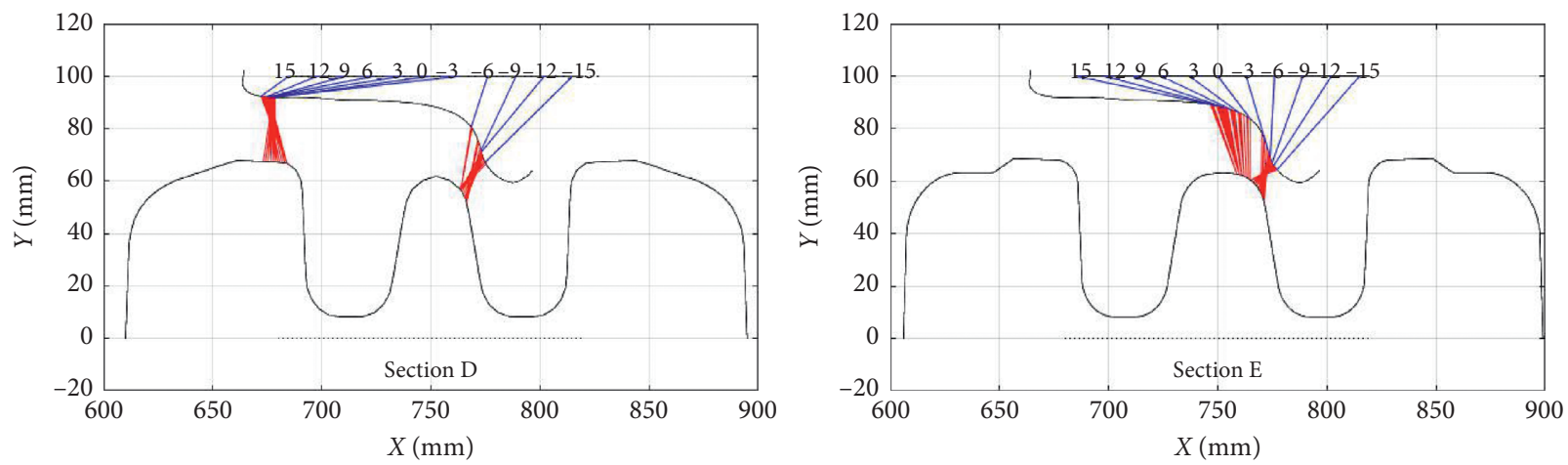

(d)
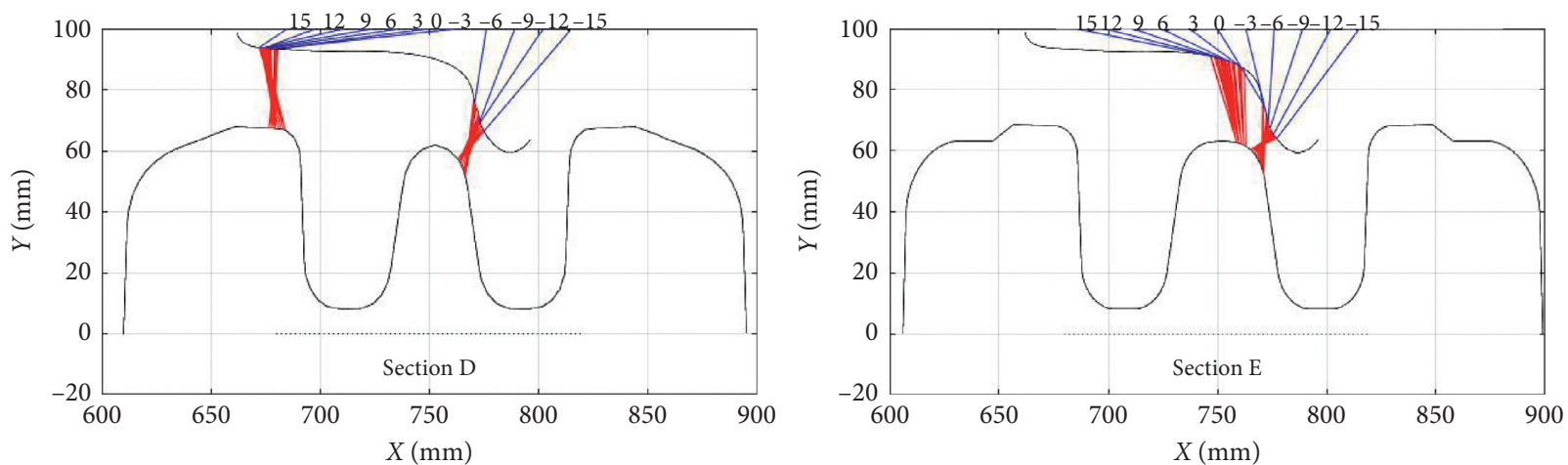

(e)

FIGURE 5: Distribution of wheel-rail contact pairs. (a) Wheel nominal profile. (b) Wheel profile I. (c) Wheel profile II. (d) Wheel profile III. (e) Wheel profile IV.

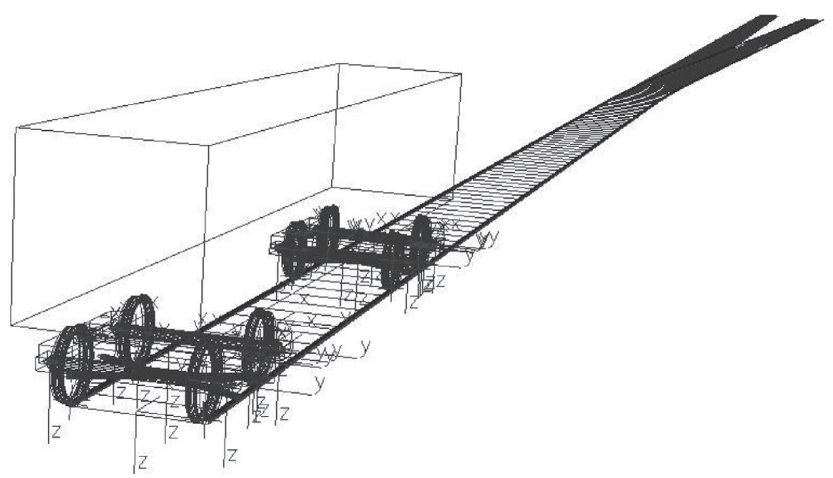

Figure 6: The vehicle-turnout system dynamic model. 
TABLE 1: The parameters of the vehicle.

\begin{tabular}{|c|c|c|}
\hline Parameters & Values & Units \\
\hline The mass of carbody & 100000 & $\mathrm{~kg}$ \\
\hline The rolling moment of inertia of carbody & 48000 & $\mathrm{~kg} \cdot \mathrm{m}^{2}$ \\
\hline The nodding moment of inertia of carbody & 440000 & $\mathrm{~kg} \cdot \mathrm{m}^{2}$ \\
\hline The yawing moment of inertia of carbody & 445000 & $\mathrm{~kg} \cdot \mathrm{m}^{2}$ \\
\hline The mass of bolster & 800 & $\mathrm{~kg}$ \\
\hline The rolling moment of inertia of bolster & 240 & $\mathrm{~kg} \cdot \mathrm{m}^{2}$ \\
\hline The nodding moment of inertia of bolster & 20 & $\mathrm{~kg} \cdot \mathrm{m}^{2}$ \\
\hline The yawing moment of inertia of bolster & 240 & $\mathrm{~kg} \cdot \mathrm{m}^{2}$ \\
\hline The mass of side frame & 500 & $\mathrm{~kg}$ \\
\hline The rolling moment of inertia of side frame & 20 & $\mathrm{~kg} \cdot \mathrm{m}^{2}$ \\
\hline The nodding moment of inertia of side frame & 200 & $\mathrm{~kg} \cdot \mathrm{m}^{2}$ \\
\hline The yawing moment of inertia of side frame & 200 & $\mathrm{~kg} \cdot \mathrm{m}^{2}$ \\
\hline The mass of carrying-saddle & 27 & $\mathrm{~kg}$ \\
\hline The rolling moment of inertia of carrying-saddle & 0.4 & $\mathrm{~kg} \cdot \mathrm{m}^{2}$ \\
\hline The nodding moment of inertia of carrying-saddle & 0.2 & $\mathrm{~kg} \cdot \mathrm{m}^{2}$ \\
\hline The yawing moment of inertia of carrying-saddle & 0.4 & $\mathrm{~kg} \cdot \mathrm{m}^{2}$ \\
\hline The mass of wedge & 10 & $\mathrm{~kg}$ \\
\hline The rolling moment of inertia of wedge & 0.06 & $\mathrm{~kg} \cdot \mathrm{m}^{2}$ \\
\hline The nodding moment of inertia of wedge & 0.06 & $\mathrm{~kg} \cdot \mathrm{m}^{2}$ \\
\hline The yawing moment of inertia of wedge & 0.08 & $\mathrm{~kg} \cdot \mathrm{m}^{2}$ \\
\hline The mass of wheelset & 1200 & $\mathrm{~kg}$ \\
\hline The rolling moment of inertia of wheelset & 800 & $\mathrm{~kg} \cdot \mathrm{m}^{2}$ \\
\hline The nodding moment of inertia of wheelset & 110 & $\mathrm{~kg} \cdot \mathrm{m}^{2}$ \\
\hline The yawing moment of inertia of wheelset & 800 & $\mathrm{~kg} \cdot \mathrm{m}^{2}$ \\
\hline The longitudinal stiffness of the secondary suspension & 1.8 & $\mathrm{MN} / \mathrm{m}$ \\
\hline The lateral stiffness of the secondary suspension & 1.8 & $\mathrm{MN} / \mathrm{m}$ \\
\hline The vertical stiffness of the secondary suspension & 2.61 & $\mathrm{MN} / \mathrm{m}$ \\
\hline The longitudinal stiffness of the primary suspension & 14 & $\mathrm{MN} / \mathrm{m}$ \\
\hline The lateral stiffness of the primary suspension & 10 & $\mathrm{MN} / \mathrm{m}$ \\
\hline The vertical stiffness of the primary suspension & 170 & $\mathrm{MN} / \mathrm{m}$ \\
\hline
\end{tabular}

of the wear wheel is lower than that of the standard wheel. Compared with other worn profiles, the lateral displacement of profile II before the theoretical nose is the smallest, close to $0 \mathrm{~mm}$, but the lateral displacement in the transition area is larger. The lateral displacement of the profile IV in the transition region is the smallest and the value is $4 \mathrm{~mm}$, and the lateral displacement before the theoretical nose is $2 \mathrm{~mm}$. It could be inferred that the worn profile could effectively reduce the lateral displacement of the wheel when it passes through the frog.

From Figure 7(b), it can be seen that the vertical displacement of all profiles reaches the maximum value in the throat area, and the variation amplitude of the vertical displacement in the theoretical nose and transition area is relatively small, which is stable near a fixed value. The maximum vertical displacement of the standard profile is $8 \mathrm{~mm}$. In the worn profiles, the maximum vertical displacement of profile IV is the largest; the value is $12 \mathrm{~mm}$. The maximum vertical displacement of profile I is the smallest, and the value is $9 \mathrm{~mm}$. It could be concluded that the worn profile might aggravate the vertical displacement of the wheel through the frog to a certain degree.

From Figure 7(c), it can be concluded that the vertical contact force of each profile after the tip of the theory (throat area) reaches the maximum and gradually decreased at both ends. The maximum vertical contact force of the standard profile is the largest, reaching $750 \mathrm{kN}$. A maximum vertical contact force of profile IV is the smallest, with a value of $320 \mathrm{kN}$. On the whole, the vertical contact force of the worn profile is less than that of the standard profile.

As can be seen from Figure $7(\mathrm{~d})$, the vibration acceleration of all profiles entering the frog and leaving the frog is relatively large. In the whole process of passing the frog, the vibration acceleration of the worn profile is less than that of the standard profile. The maximum vibration acceleration of the carbody is $3.3 \mathrm{~m} / \mathrm{s}^{2}$ for the standard profile and it is $1.1 \mathrm{~m} /$ $\mathrm{s}^{2}$ for the worn profile, reduced by $66.7 \%$. This characteristic is obvious in the throat area and transition area. Of all the worn profiles, profile IV performs best, and its vibration acceleration is basically the smallest in the whole process.

It is inferred that wheel profile abrasion has a great influence on the dynamic interaction between vehicle and fixed frog. In the crossing panel, the dynamic responses are the local maximum when the wheel transfers from the wing rail to the nose rail, which is the possible reason for the serious wear of the nose rail. For the worn wheel profiles measured in this study, wheel profile wear relieves the lateral and vertical dynamic responses. It could be explained by changes of wheel-rail contact points between the wheel with different profiles and fixed frog. 


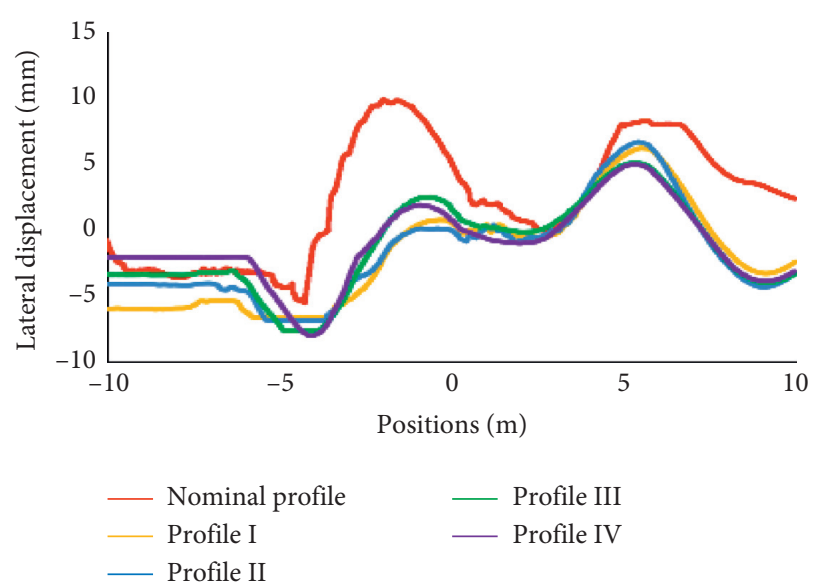

(a)

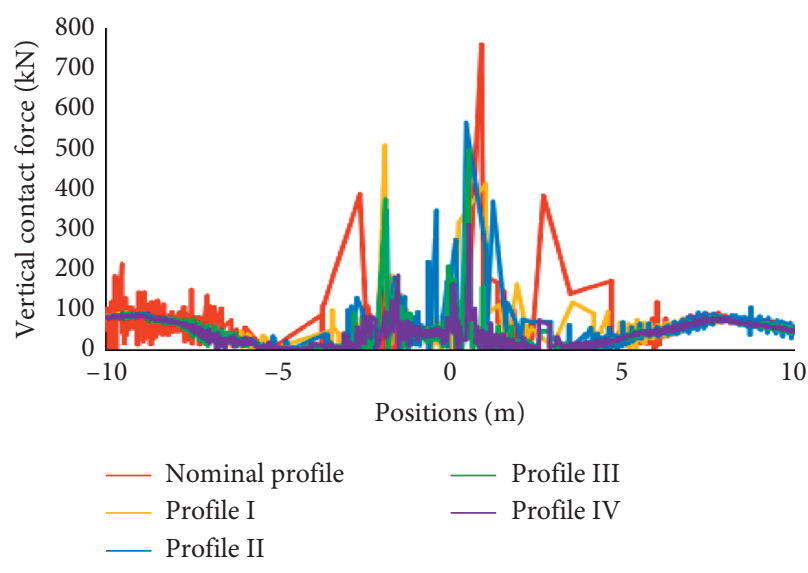

(c)

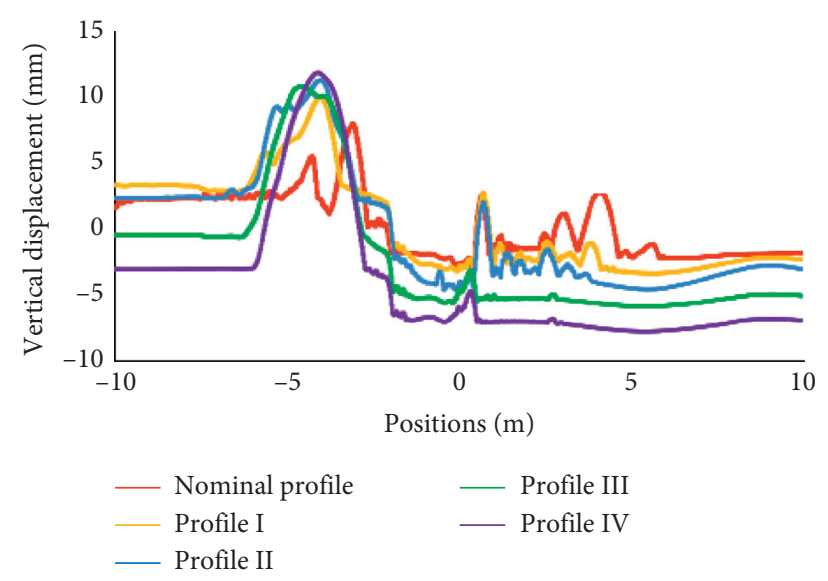

(b)

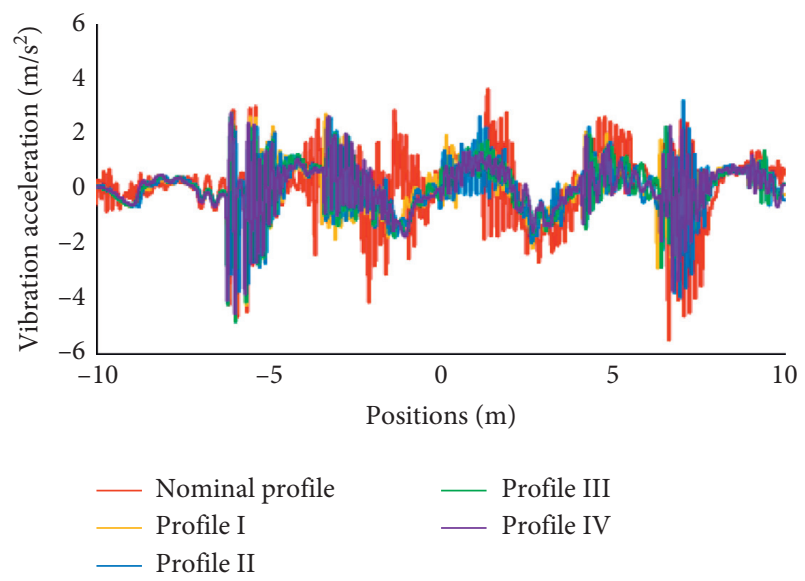

(d)

FIGURE 7: The comparison of the dynamic interaction of vehicle and fixed frog. (a) Lateral displacement of wheelset. (b) Vertical displacement of wheelset. (c) Vertical contact force. (d) Vibration acceleration of carbody.

The dynamic interaction between the wheel and the fixed frog is reduced due to the sudden changes of the contact points in the vertical direction.

\section{Analysis of Wheel-Rail Contact Patch and Distribution of Equivalent Stresses}

5.1. Finite Element Model. The fixed frog profiles have been designed to be changed along the crossing panel and the plastic characteristics of wheel and fixed frog have been considered in the finite element model. So it is applied to determine the contact patches and calculate the equivalent stresses.

The ABAQUS software is utilized to establish the finite element models of the wheel-fixed frog contact, in which the wheel profiles at different wear stages are considered. The wheelset, stock rail, and fixed frog are divided into a finite number of elements, shown in Figure 8. The rail bottom is fully constrained. The lateral displacement and contact force calculated in Simpack software are used as inputs of the finite element model.

The accuracy of calculation mainly depends on the sizes of elements, but it is often a trade-off between accuracy and calculative efficiency. To overcome this problem, the wheelset and rails are meshed into elements with the size of $1 \mathrm{~mm}$ in the potential contact areas. However, those elements that are far away from the contact area are meshed with bigger element sizes; see Figure 9.

In the finite element model, a bilinear kinetic intensify model is used to represent the elastoplastic characteristics of the wheel-rail materials, which conforms to von Mises yield criterion and kinetic hardening rule. The von Mises yield criterion is expressed by

$$
\sigma_{e}=\sqrt{\frac{1}{2}\left[\left(\sigma_{1}-\sigma_{2}\right)^{2}+\left(\sigma_{2}-\sigma_{3}\right)^{2}+\left(\sigma_{3}-\sigma_{1}\right)^{2}\right]} \geq \sigma_{s}
$$

where $\sigma_{e}$ is the equivalent stress; $\sigma_{1}, \sigma_{2}$, and $\sigma_{3}$ are the principal stresses; and $\sigma_{s}$ is the yield stress of the material.

When the equivalent stress $\sigma_{e}$ satisfies equation (1), the material begins to deform plastically. The kinetic hardening rule is expressed by

$$
\sigma= \begin{cases}E_{e} \varepsilon, & \varepsilon \leq \varepsilon_{s}, \\ \sigma_{s}+E_{p}\left(\varepsilon-\varepsilon_{s}\right), & \varepsilon>\varepsilon_{s}\end{cases}
$$

where $E_{e}$ is Young's modulus; $E_{p}$ is the strain hardening modulus; and $\varepsilon_{s}$ is the total strain at yield point. $E_{e}, E_{p}$, and 


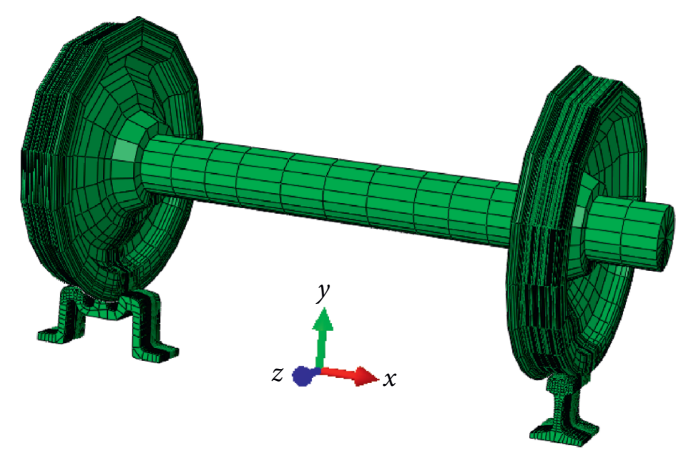

FIgURe 8: The wheel-rail finite element model.
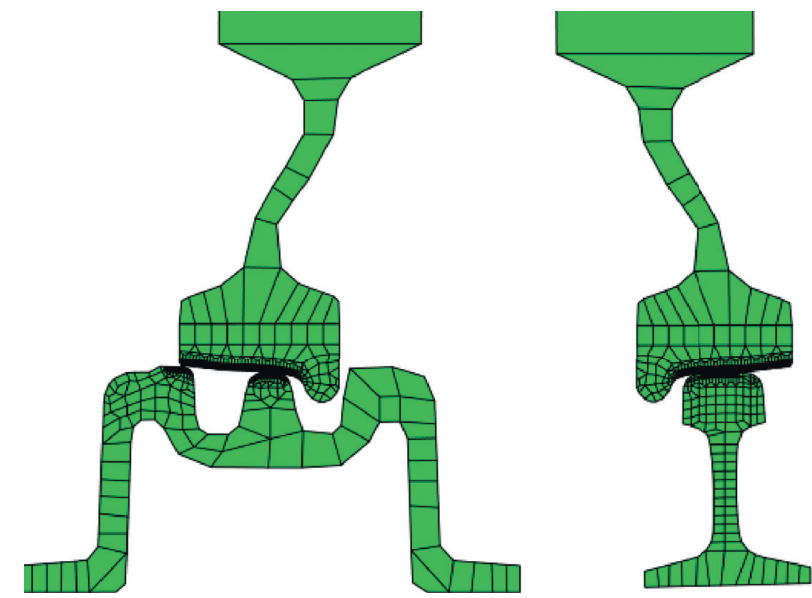

FIgure 9: The two-dimensional finite elements of wheel-rail contact.

$\sigma_{s}$ of wheel and rail are listed in Table 2 and the equivalent stress-strain curve of wheel-rail material is shown in Figure 10.

5.2. Calculation Results. The dynamic responses of the vehicle and fixed frog, such as normal contact force and lateral displacement of wheelset are utilized as inputs for the finite element model. The finite element method could simulate the internal stresses of wheel and fixed frog, and the calculations of von Mises stresses for the selected profiles at Sections D and E are shown in Figure 11.

At Section D, the wheels with nominal profile, profiles I and II, contact with the nose rail of the fixed frog. With the wheel profiles wearing, the wheel tread wears more seriously than the outer side of the wheel, so the wheels with profiles III and IV contact with the wing rail of the fixed frog. The wheels with nominal profile and all worn profiles contact with nose rail at Section E. It means that the wheels have already transferred onto the nose rail from the wing rail. And the above kinetic results show that the wheels have an impact on the nose rail at the instantaneous transition from wing rail to nose rail. And that makes the nose rail wear seriously.

The maximum von Mises stresses of wheel and rail exceed the material yield limit, which is located in the region of $2.3-3.5 \mathrm{~mm}$ right under the surface. The material of wheel and fixed frog in this region forms a plastic deformation. When the plastic deformation accumulates to limit value, the internal cracks would occur. The wheel profile wear cannot always decrease the von Mises stress. At Section E, the wheel profiles wear worsens the wheel-rail conditions, which leads to increasing the von Mises stress.

It can be seen from the above figure that the maximum von Mises stress decreases with the increase of wear at Section D, from $1336 \mathrm{MPa}$ of standard profile to $881.3 \mathrm{MPa}$ of profile IV, with a reduction of $34 \%$.

From the finite element calculation, for the wheel with profile III or IV, it is known that the wheels contact with the wing rail at Section $\mathrm{D}$, and at Section $\mathrm{E}$, the wheels contact with the nose rail. It could be concluded that the wheels transfer to the nose rail at the range of Section D and Section E while, for the wheel with the nominal profile, profile I or II, at Section D and Section E, the wheels contact with nose rail. And the wheels contact with the wing rail at Section C. So, the wheels transfer from wing rail to nose rail at the range of Section C and Section D. The profile wear makes the transition position backwards, which is good for the nose rail because the top head of nose rail is wider.

As shown in Table 3, with the increase of wheel wear, the contact spot area increased from $73 \mathrm{~mm}^{2}$ to $152 \mathrm{~mm}^{2}$ in Section D. The contact position of the standard profile, profile I and profile II, is in the nose rail, and the contact 
TABLE 2: The values of wheel-rail Young's modulus, kinetic hardening modulus, and yield stress.

\begin{tabular}{lccc}
\hline & Wheel & Fixed frog & Stock rail \\
\hline Young's modulus $\left(E_{e}\right)(\mathrm{GPa})$ & 206 & 210 & 206 \\
Strain hardening modulus $\left(E_{p}\right)(\mathrm{GPa})$ & 20.6 & 21 & 20.6 \\
Yield stress $\left(\sigma_{s}\right)(\mathrm{MPa})$ & 540 & 400 & 460 \\
\hline
\end{tabular}
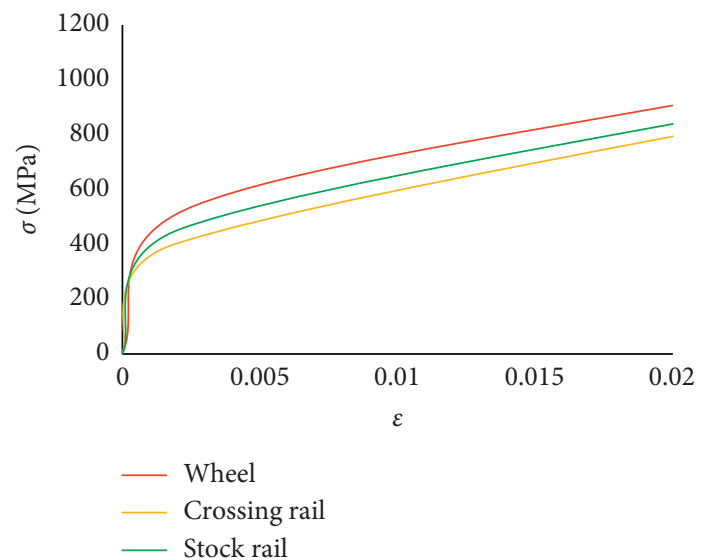

FIGURE 10: Equivalent stress-strain curve of wheel-rail materials.
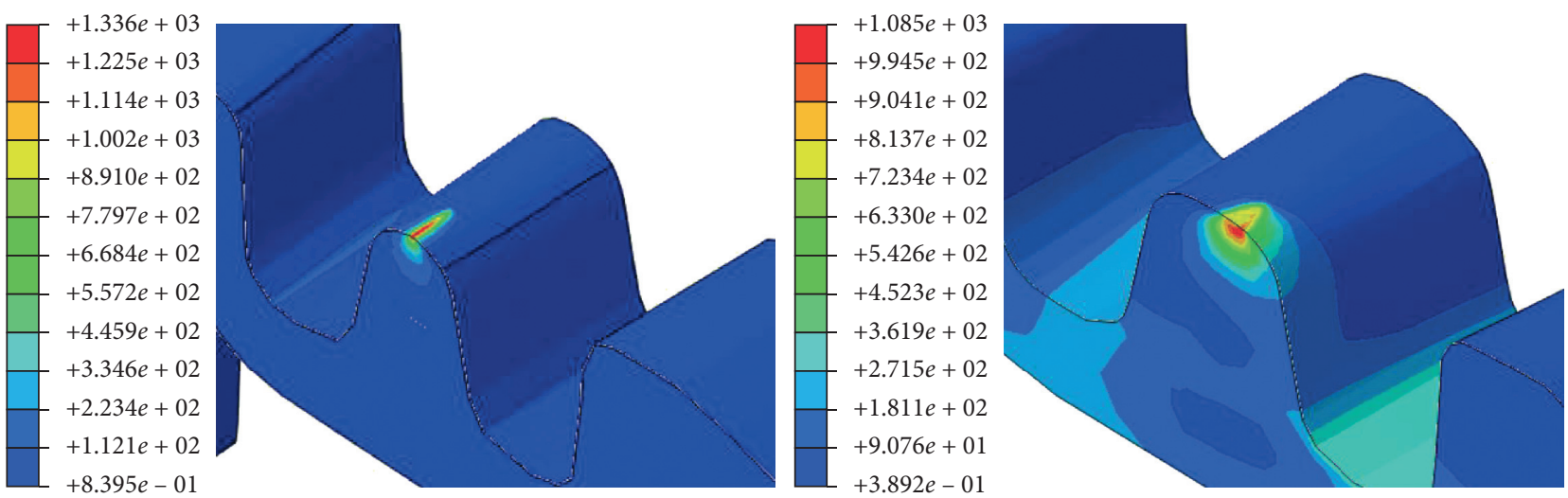

(a)
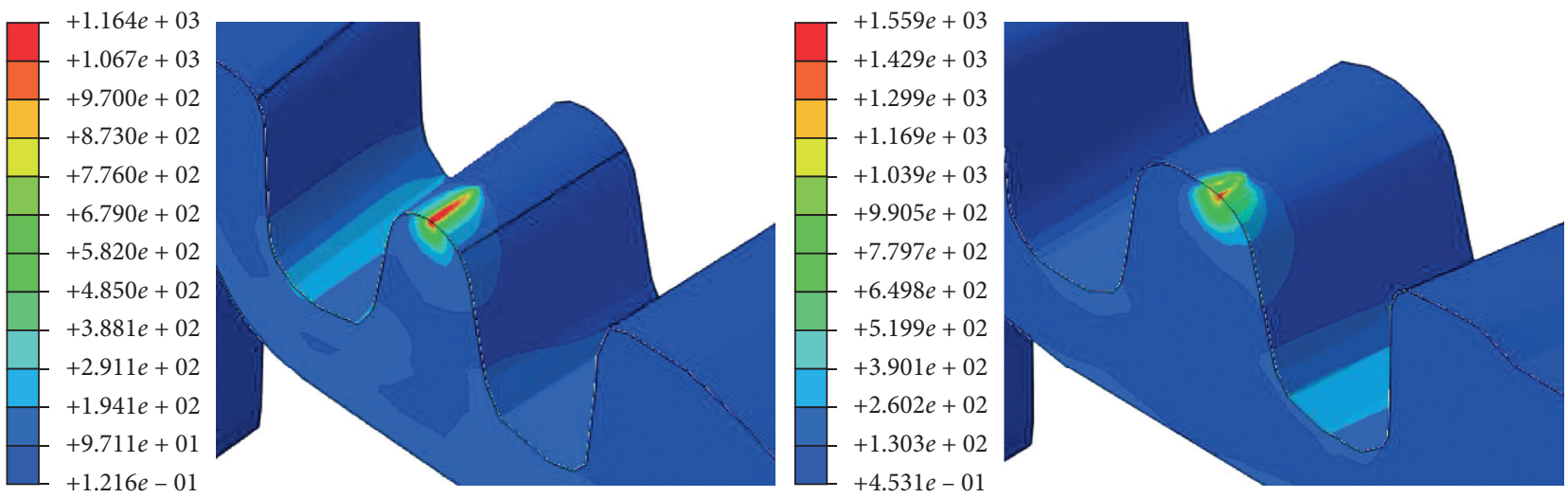

(b)

Figure 11: Continued. 

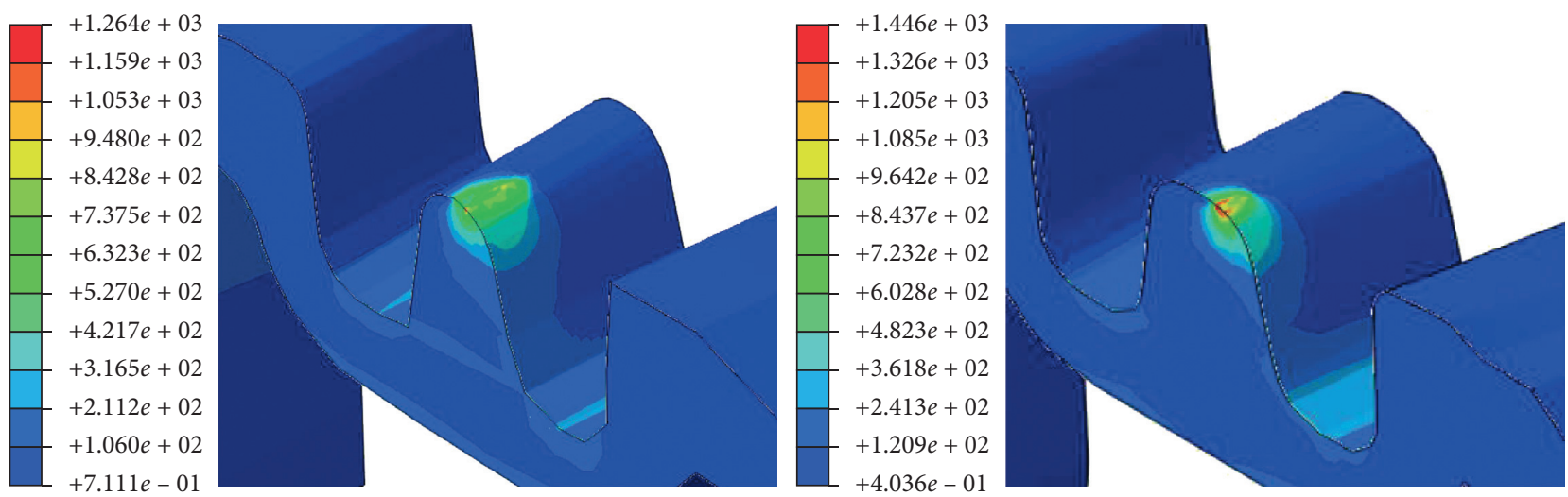

(c)
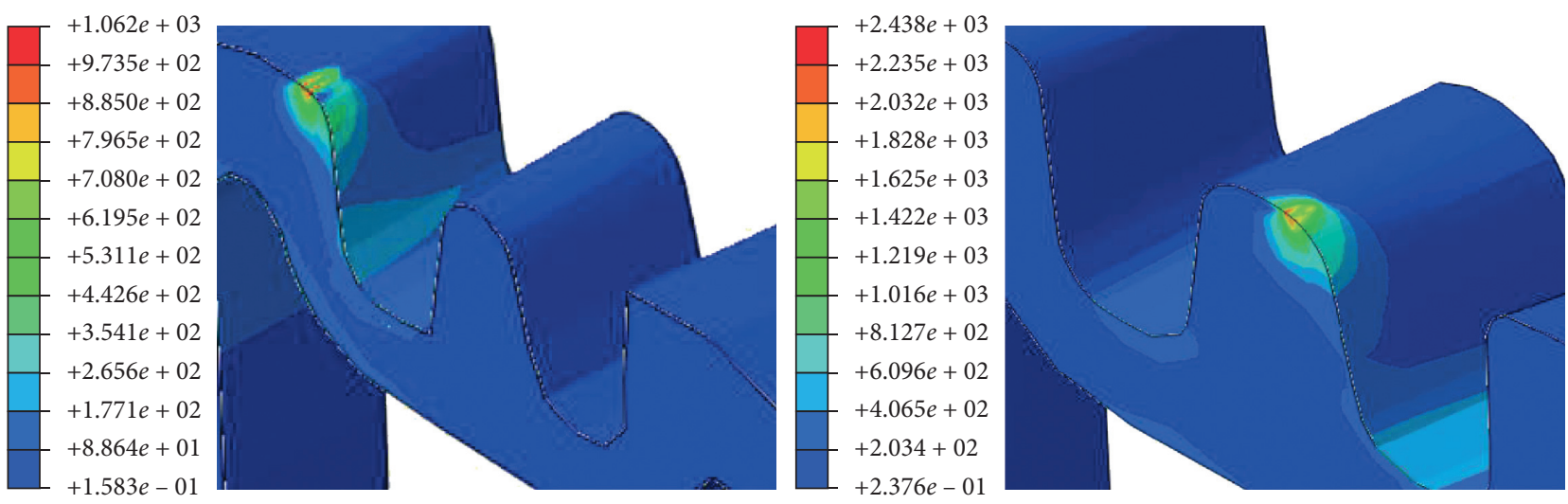

(d)
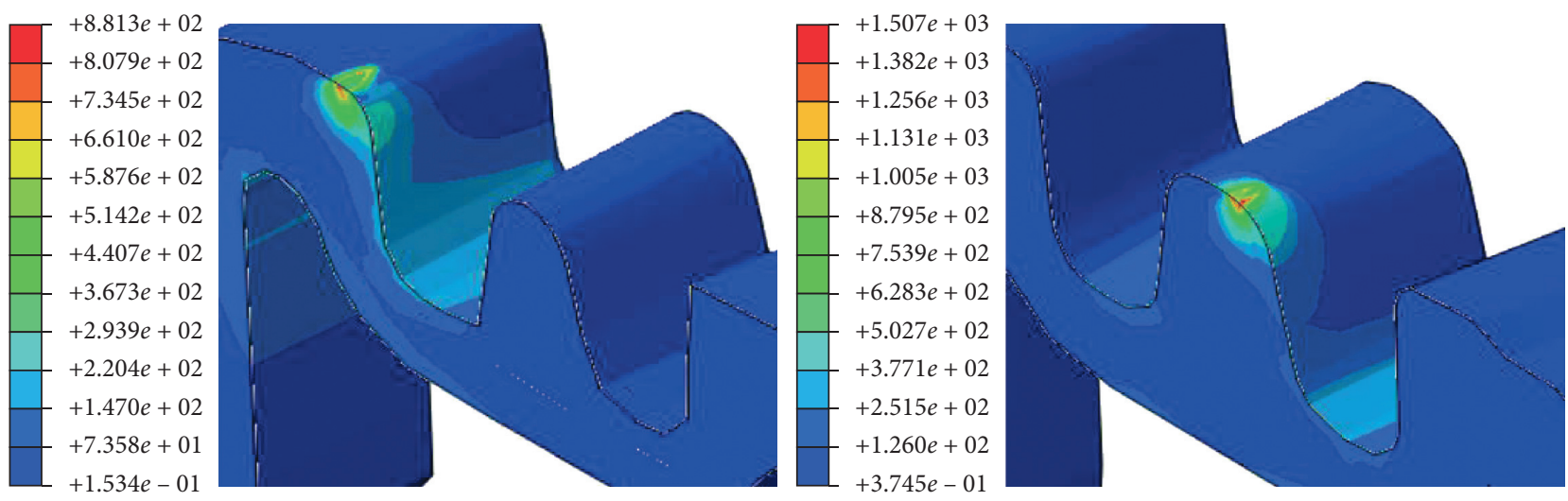

(e)

FIGURE 11: von Mises stresses of wheel-rail contact (the above for Section D and the below for Section E). (a) Wheel nominal profile. (b) Wheel profile I. (c) Wheel profile II. (d) Wheel profile III. (e) Wheel profile IV.

position of the other worn profile is in the wing rail. When the position of the contact spot changes from the nose rail to the wing rail, the contact area decreases slightly from $110 \mathrm{~mm}^{2}$ to $105 \mathrm{~mm}^{2}$. The contact spot area fluctuates up and down in the range of $80 \mathrm{~mm}^{2}$ as the wheel wear deepens in Section E. The contact spot size of profile IV at Section E is $104 \mathrm{~mm}^{2}$, which is $30 \%$ more than that of the standard profile. And the location of the contact spot is always on the nose rail.

In the transition process, there are two-point contact between wheel and fixed frog and the contact shapes are shown in Figure 12. The contact status is long and narrow. The length of the contact status is about $21 \mathrm{~mm}$ to $28 \mathrm{~mm}$, and its width is about $2 \mathrm{~mm}$ to $5 \mathrm{~mm}$. The contact area is very 
TABLe 3: The contact spot size and contact position of each type of profile at Section D and Section E.

\begin{tabular}{|c|c|c|c|c|c|c|c|c|}
\hline & \multicolumn{4}{|c|}{ Section D } & \multicolumn{4}{|c|}{ Section E } \\
\hline & $\begin{array}{c}\text { Area } \\
\left(\mathrm{mm}^{2}\right)\end{array}$ & $\begin{array}{l}\text { Longitudinal length } \\
\qquad(\mathrm{mm})\end{array}$ & $\begin{array}{l}\text { Lateral length } \\
\quad(\mathrm{mm})\end{array}$ & Positions & $\begin{array}{l}\text { Area } \\
\left(\mathrm{mm}^{2}\right)\end{array}$ & $\begin{array}{l}\text { Longitudinal length } \\
\qquad(\mathrm{mm})\end{array}$ & $\begin{array}{l}\text { Lateral length } \\
(\mathrm{mm})\end{array}$ & Positions \\
\hline $\begin{array}{l}\text { Standard } \\
\text { profile }\end{array}$ & 73 & 23 & 3 & Nose rail & 80 & 16 & 7 & Nose rail \\
\hline Profile I & 98 & 21 & 5 & Nose rail & 85 & 16 & 5 & Nose rail \\
\hline Profile II & 110 & 20 & 6 & Nose rail & 60 & 17 & 6 & Nose rail \\
\hline Profile III & 105 & 22 & 5 & Wing rail & 58 & 21 & 3 & Nose rail \\
\hline Profile IV & 152 & 26 & 8 & Wing rail & 104 & 19 & 6 & Nose rail \\
\hline
\end{tabular}

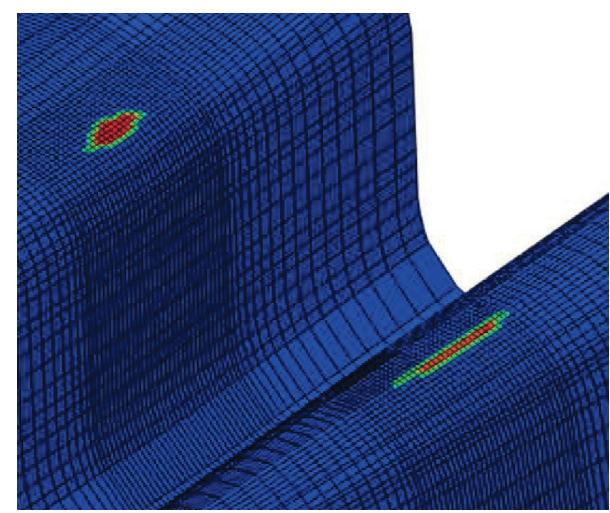

FIGURE 12: Contact status on the nose and wing rail.

small so that the wheel and frog damage is more serious than the common rail. In addition, the centers of the contact status on the wing and nose rails are not found in the same longitudinal position. Thus, a relative slip occurs between the wheel and frog, thereby causing both to wear.

\section{Conclusions}

The influences of wheel profile wear on the static and dynamic contact performance of the vehicle and fixed frog in heavy haul railway are simulated in this article. Both wheel profiles at different wear stages and the changing cross sections of fixed frog are as inputs for the simulation. According to the simulation, it could be summarized that

(1) Compared with the standard profile, the maximum lateral displacement of the worn profile can be reduced by up to $9 \mathrm{~mm}$, but the vertical displacement increases by up to $4 \mathrm{~mm}$. The vertical contact force can be reduced from $750 \mathrm{kN}$ to $320 \mathrm{kN}$, and the decrease is as high as $57.3 \%$. In addition, the vibration acceleration is also reduced. The wheel profile wear strongly affects the dynamic interaction of the vehicle and fixed frog.

(2) The vertical contact force reaches a maximum of $750 \mathrm{kN}$ after passing through the theoretical nose of crossing at the range of $20 \mathrm{~mm}-40 \mathrm{~mm}$ nose rail width. For the wheels with different wear stages profiles, they transit from the wing rail to the nose rail at the width range of $20 \mathrm{~mm}$ and $40 \mathrm{~mm}$ when passing through the fixed frog in the facing move. There are impacts on the nose rail, which make the nose rail wear seriously.

(3) The wheel profile wear affects strongly the distribution of the wheel-rail von Mises stress and the contact patches. The area of the contact spot increases with the increase of the profile wear, which makes the von Mises stress decrease accordingly. The von Mises stress of profile IV decreases by $34 \%$ compared with the standard profile at $30 \mathrm{~mm}$ of nose rail width. The larger the contact area of the nose rail, the larger the loading area, and the lighter the wear, the wider the top surface of the nose rail, which is good for the nose rail.

This research could provide fundamental guidance for the profiles design and optimization of fixed frog and wheel and grinding of the fixed frog.

\section{Data Availability}

The data used to support the findings of this study are included within the article.

\section{Conflicts of Interest}

The authors declare no conflicts of interest with respect to the research, authorship, and/or publication of this article.

\section{Acknowledgments}

This study was financially supported by National Natural Science Foundation of China (51775031) and Beijing Postdoctoral Research Foundation.

\section{References}

[1] H. Zhao, "Discussion on technical indicators of turnout on Daqin heavy haul railway," Railway Engineering, vol. 4, pp. 89-91, 2010.

[2] J. Yan and M. Fu, Vehicle Engineering, China Railway Publishing House, Beijing, China, 2009.

[3] C. Li, "Research on movable frog reconstruction scheme of no. 18 turnout with $75 \mathrm{~kg} / \mathrm{m}$ rail used in Datong-Qinhuangdao railway," Railway Engineering, vol. 8, pp. 117-120, 2012. 
[4] T. Zhao, Y. Luo, and Y. Xu, "Research on no. 18 unmovable frog with $75 \mathrm{~kg} / \mathrm{m}$ rail used in Datong-Qinhuangdao heavy haul railway," Railway Standard Design, vol. 2, pp. 7-11, 2012.

[5] R. F. Lagos, A. Alonso, J. Vinolas, and X. Pérez, "Rail vehicle passing through a turnout: analysis of different turnout designs and wheel profiles," Proceedings of the Institution of Mechanical Engineers, Part F: Journal of Rail and Rapid Transit, vol. 226, no. 6, pp. 587-602, 2012.

[6] Y. Q. Sun, C. Cole, and M. McClanachan, "The calculation of wheel impact force due to the interaction between vehicle and a turnout," Proceedings of the Institution of Mechanical Engineers, Part F: Journal of Rail and Rapid Transit, vol. 224, no. 5, pp. 391-403, 2010.

[7] Z. Ren and S. Sun, "Research on the wheel/rail contact geometry relationship in the turnout zone," Engineering Mechanics, vol. 25, no. 11, pp. 223-230, 2008.

[8] K. Gao and Z. Ren, "Dynamic performance analysis of wagon with $25 \mathrm{t}$ axle load through turnout," Journal of Beijing Jiaotong University, vol. 30, no. 4, pp. 105-108, 2006.

[9] Z. Ren, Z. Liu, and X. Jin, "Study on the influence of the top surface lower value of nose rail on the wheel/turnout dynamic interaction," Journal of the China Railway Society, vol. 31, no. 2, pp. 79-83, 2009.

[10] W. Zhai and K. Wang, "The operation safety assessment of locomotive and vehicle passing through the branch of turnout," Journal of Tongji University (Nature Science), vol. 32, no. 3, pp. 382-386, 2004.

[11] X. Cai and C. Li, "The wheel-rail contact irregularity in highspeed frog," Journal of Southwest Jiaotong University, vol. 43, no. 1, pp. 86-90, 2008.

[12] J. Li, J. Zhang, J. Zhang et al., "The elastic-plastic contact analysis of locomotive wheel and fixed frog," Railway Locomotive and Motor Car, vol. 9, pp. 23-26, 2014.

[13] M. Wiest, E. Kassa, W. Daves et al., "Assessment of methods for calculating contact pressure in wheel-rail/switch contact," Wear, vol. 265, no. 9-10, pp. 1439-1445, 2008.

[14] P. Martin, D. Werner, and O. Heinz, "A wheel passing a crossing nose: dynamic analysis under high axle loads using finite element modeling," Proceedings of the Institution of Mechanical Engineers. Part F: Journal of Rail and Rapid Transit, vol. 226, no. 6, pp. 603-611, 2008.

[15] M. Pletz, W. Daves, and H. Ossberger, "A wheel set/crossing model regarding impact, sliding and deformation-explicit finite element approach," Wear, vol. 294-295, pp. 446-456, 2012.

[16] J. Xu, P. Wang, L. Wang et al., "Effects of profile wear on wheel-rail contact conditions and dynamic interaction of vehicle and turnout," Advances in Mechanical Engineering, vol. 8, no. 1, pp. 1-14, 2016.

[17] R. Chen, J. Chen, P. Wang et al., "Impact of wheel profile evolution on wheel-rail dynamic interaction and surface initiated rolling contact fatigue in turnouts," Wear, vol. 438439, Article ID 203109, 2019. 